\title{
Association of circulating omentin-1 level with lung cancer in smokers
}

\author{
Mohammad Hassan Khadem Ansari ${ }^{1}$, Mahdia Gholamnejad ${ }^{2}$, Khadije Meghrazi*1, \\ Hamid Reza Khalkhali ${ }^{3}$
}

Received: 12 Mar 2018

Published: 29 Dec 2018

\begin{abstract}
Background: Omentin has recently been considered as an adipokine secreted from visceral fat and is expressed in the lungs, heart, ovary etc. Various studies have shown that omentin may have an anti-inflammatory role in the inflammatory process and the amount of omentin alters in some cancers, such as colorectal, prostate and renal cells cancers, changes. The serum level of omentin, however, remains unknown in non-patient smokers and the smokers afflicted with lung cancer. Therefore, this study examines the serum levels of omentin in smokers suffering from lung cancer.

Methods: The amount of serum omentin was measured in 45 patients with lung cancer and 61 age - and sex - matched controls ( 30 smokers and 31 non-smokers) using enzyme-linked immunosorbent assay (ELISA) kit. Data were analyzed using SPSS-16, and oneway analysis of variance and Scheffe post hoc test were used to determine and compare the serum levels of omentin in different types of lung malignancies. Significance level was set at $\mathrm{p} \leq 0.05$.

Results: The amount of circulating omentin for healthy non-smokers and non-patient smokers was $3.55 \pm 0.57 \mathrm{ng} / 1 \mathrm{and} 5.43 \pm 1.95 \mathrm{ng} / \mathrm{l}$, respectively $(\mathrm{p}<0.001)$. The serum level of omentin was $3.63 \pm 0.70 \mathrm{ng} / 1$ for smokers afflicted with cancer $(\mathrm{p}<0.001$ compared with nonpatient smokers: $5.43 \pm 1.95)$.

Conclusion: The meaningful decrease in omentin levels in smokers with lung cancer can be considered as a risk factor in smokers and can use as a significant factor in the prognosis of lung cancer in these people.
\end{abstract}

Keywords: Smoker, Omentin, Lung cancer

Conflicts of Interest: None declared

Funding: West Azerbaijan University of Medical Sciences and Health Services

*This work has been published under CC BY-NC-SA 1.0 license.

Copyright $\odot$ Iran University of Medical Sciences

Cite this article as: Khadem Ansari MH, Gholamnejad M, Meghrazi Kh, Khalkhali HR. Association of circulating omentin-1 level with lung cancer in smokers. Med J Islam Repub Iran. 2018 (29 Dec);32:133. https://doi.org/10.14196/mjiri.32.133

\section{Introduction}

Lung cancer is one of the pulmonary diseases and is the uncontrolled growth of the epithelial cells of the lung and its prevalence in smokers is higher as compared to nonsmokers. Around the world, lung cancer is the most common cancer in terms of outbreaks and death. In 2012, 1.8 million new items $(12.9 \%$ of all people with all types of cancers diagnosed in this year) and 1.6 million deaths from lung cancer were reported (1). Being among the five major cancers in Iran, the lung cancer afflicts a large number of

Corresponding author: Khadije Meghrazi, Kmeghrazi@gmail.com

1. Department of Biochemistry, Faculty of Medicine, Urmia University of Medical Sciences, Urmia, Iran

2. Pulmonology Department, Urmia University of Medical Sciences, Urmia, Iran

3. Department of Epidemiology and Biostatistics, faculty of medicine, Urmia University of medical sciences, Urmia, Iran people about $80 \%$ of which included by smokers (2). Adipose tissue is known as an endocrine and immune organ (3). Until recently, adipose tissue was thought to affect only lipid metabolism and glucose homeostasis. This tissue is now identified as the secretion source of more than 20 types of different hormones and molecules called adipocytokine or adipokine which play significant biological roles in the vascular system, glucose homeostasis, reproduction, bone metabolism, immune system and cancer (4$5)$.

$\uparrow$ What is "already known" in this topic:

There are studies about the role of omentin hormone in a variety of diseases, such as cancer; however, its serum levels in patients with lung cancer are unknown.

$\rightarrow$ What this article adds:

Cigarettes can increase the level of hormones in the serum and the level of serum omentin hormone changes in smokers who have lung cancer. 
As one of the adipokines, omentin (or intelectin) was first found in the intestinal paneth cells, which reacts with galactofuranose in the carbohydrate part of the cell wall of the bacteria and is involved in intestinal defense mechanisms against pathogenic bacteria (6). Omentin-1 is the type of omentin which is mostly addressed in research papers. There is another homolog of omentin which is called omentin-2. About $83 \%$ of its amino acids are identical to that of omentin-1. Omentin 1 is also expressed in the lungs, heart, ovary, and placenta (7-10) and is secreted as a new adipokine in visceral adipose tissue. The Laboratory experiments show that omentin increases the level of insulin sensitivity (i.e. increases the glucose uptake by insulin) (10) and activates Akt signaling pathway. Akt is a serine / threonine protein kinase that plays an important role in multiple cellular actions such as glucose metabolism, cell proliferation and apoptosis as a secondary messenger (7). Also, the increase in omentin leads to a decrease in the level of CRP in serum and decreases the effects of TNF- $\alpha$ (tumor necrosis factor alpha that increases in inflammatory conditions). So there can be a connection between omentin and inflammation (7, 11-12). Chronic inflammation increases the risk of cancer (12), and in some cancers, inflammation occurs before the onset of cancer and malignancy $(1,13)$. Cigarette smoking causes chronic inflammation in the lungs, and inflammatory mechanisms also cause a lung tumor under the influence of smoking (12).

The amount of gene expression of this adipokine is reduced in the epithelium of smokers' airways (14), and though it is known that omentin is secreted from the epithelial cells of the lung, it is not clear whether there is an increase or decrease in the serum level of this hormone in smokers with lung cancer.

\section{Methods}

\section{Study population}

The patient group of this study were 45 smoker male patients referred to the pulmonary clinic of the Imam Khomeini hospital in Urmia, Iran. The control group consisted of 61 males with no history of illness and with matched of age and BMI (Body mass index) (30 smokers and 31 nonsmokers). The protocol of the study followed the principles of the Declaration of Helsinki. All the subjects signed the informed consent form. Initially, careful lung examinations were conducted and then the tissue biopsy specimens were sent to the histopathology laboratory for more accurate diagnosis. The blood and urine parameters for all the individuals in both groups were within normal ranges.

\section{Laboratory analysis}

Before starting any type of therapeutic treatment in patients, peripheral blood was drawn from subjects after measuring their height and weight to calculate BMI. After separation of the serum of the samples in a cooling centrifuge and spinning at $3000 \mathrm{rpm}$ for $10 \mathrm{~min}$, the biochemical parameters such as fasting blood glucose (FBG), triglyceride (TG) and low density lipoprotein - cholesterol (LDL-c) were detected via the standard protocols using a clinical chemistry autoanalyzer (BT 3000, Italy) in the laboratory of Imam Khomeini Hospital in Urmia in the sampling day. Then serum was frozen at $-80^{\circ} \mathrm{C}$ until the analysis of omentin. Serum omentin was measured using commercially available enzyme-linked immunoassay (ELISA) kits (Bioassay technology laboratory, China) according to manufacturer's instructions. The sensitivity of the assay was 1.03 ng/l (assay range: 2-600 ng/l). The intra- and inter-assay coefficients of variance were $<8 \%$ and $<10 \%$, respectively.

\section{Statistical analysis}

All data were analyzed using the SPSS software package version 16 . The results are presented as means \pm S.D. The analyses of normally distributed variables (age and BMI and biochemical analysis) were conducted using independent- sample t-test. To determine and compare the serum levels of omentin in different types of lung malignancies, one-way analysis of variance was used and finally, Scheffe post hoc test was used as well. Kolmogorov- Smirnov test were used to determine whether or not they were normally distributed and the analyses of abnormally distributed variables were conducted with the Mann-Whitney $U$ test. Comparisons with $\mathrm{p}<0.05$ were considered to be statistically significant.

\section{Results}

The baseline characteristics of the subjects are summarized in Table 1. The mean age in the control group who did not smoke was $58.87 \pm 7.19$ whereas it was $58.65 \pm 7.82$ for the smokers in the control group. The mean BMI of these the two groups were $24.58 \pm 2.93$ and $24.10 \pm 2.93$, respectively. The mean age of the patient group was $65.13 \pm 9.32$, and the mean BMI of the patient group was $23.82 \pm 4.28$. The values of other biochemicals are given in Table 1.

Figure 1 shows the changes in the level of omentin hormone in the healthy and cancerous groups as follows: 3.55 $\pm 0.57 \mathrm{ng} / 1$ for nonsmokers and $5.43 \pm 1.95 \mathrm{ng} / \mathrm{l}$ for smokers in the control group and $3.63 \pm 0.70 \mathrm{ng} / \mathrm{l}$ for the patient group.

The amount of serum omentin was different in a variety of pulmonary malignancies. It was $3.04 \pm 0.38 \mathrm{ng} / 1$ in SCC (squamose cell carcinoma), $4.08 \pm 0.31 \mathrm{ng} / 1$ in adenocarcinoma, $3.88 \pm 0.50 \mathrm{ng} / 1$ in small cell carcinoma and $4.27 \pm 0.65 \mathrm{ng} / \mathrm{l}$ in other lung diseases (for example poorly differentiated carcinoma) according to Figure 2.

Table 1. The baseline characteristics of subjects

\begin{tabular}{lccc}
\hline Variables & $\begin{array}{c}\text { Non- smoker, non- patient } \\
(\mathrm{n}=31)\end{array}$ & $\begin{array}{c}\text { Smoker, non- patient } \\
(\mathrm{n}=30)\end{array}$ & $\begin{array}{c}\text { Smoker, patient } \\
(\mathrm{n}=45)\end{array}$ \\
\hline Age $(\mathrm{years})$ & $58.87 \pm 7.1$ & $58.65 \pm 7.82$ & $65.13 \pm 9.32$ \\
BMI $\left(\mathrm{kg} \mathrm{/m} \mathrm{m}^{2}\right)$ & $24.58 \pm 2.93$ & $24.10 \pm 2.93$ & $23.82 \pm 4.28$ \\
FBS $(\mathrm{mg} / \mathrm{dl})$ & $81.35 \pm 9.58$ & $82.16 \pm 9.45$ & $82.32 \pm 10.44$ \\
TG $(\mathrm{mg} / \mathrm{dl})$ & $95.83 \pm 7.91$ & $94.30 \pm 8.94$ & 0.061 \\
LDL-c $(\mathrm{mg} / \mathrm{dl})$ & $79.19 \pm 7.73$ & $79.26 \pm 9.31$ & 0.917 \\
\hline
\end{tabular}

Data are presented as mean \pm SD. BMI (body mass index), FBS (fasting blood sugar), TG (triglyceride), LDL-c (low-density lipoprotein-cholesterol). 


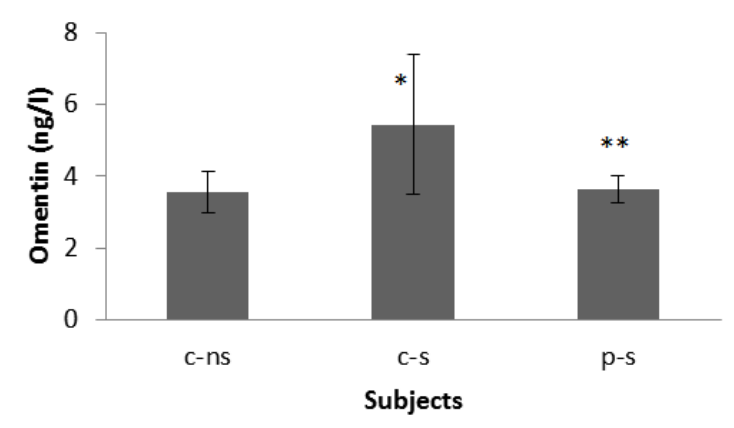

Fig. 1. The levels of omentin in the serum of subjects Data are presented as mean \pm SD. Control-nonsmoker (c-ns), control- smoker (cs) and patient- smoker (p-s). *Indicates a statistically significant difference vs. cns $(\mathrm{p}<0.05)$. ${ }^{* *}$ Indicates a statistically significant difference vs. $\mathrm{c}-\mathrm{s}(\mathrm{p}<0.05)$.

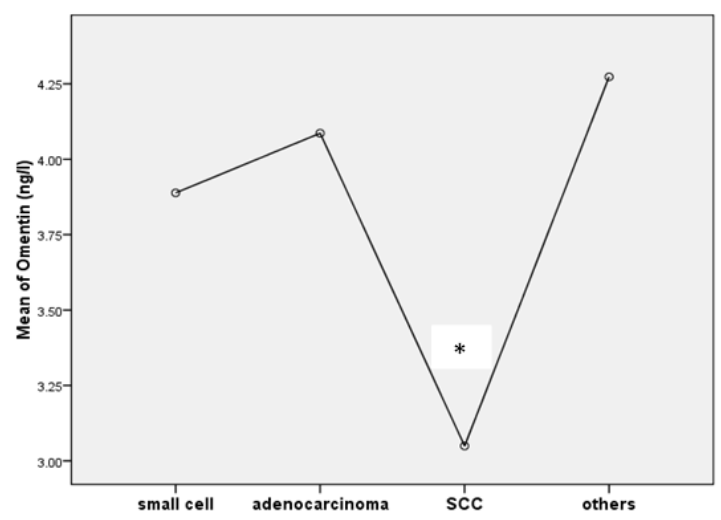

Fig. 2. Serum level of omentin in the variety of lung malignancies Decreasing plasma omentin in patients with SCC shows a significant decrease compared with other patients. Data are expressed as mean.*indicates a statistically significant difference relative to the other patients $(\mathrm{p}<0.05)$ (SCC vs adenocarcinoma, SCC vs small cell and SCC vs others).

\section{Discussion}

The present study demonstrates that the serum level of omentin increases in smokers compared to non-smokers (neither with a history of illness), whereas Brendan and colleagues in 2008 proved that the expression of the omentin gene is reduced in the epithelial cells of the airways of smokers (14). Smoking can predispose a person to inflammatory diseases (15). The level of serum omentin decreases in inflammatory diseases such as Crohn's disease (chronic inflammatory bowel disorder) and rheumatoid arthritis. In these inflammatory diseases, omentin is reduced as an antiinflammatory factor (7) and on the other hand in patients with chronic kidney disease that do not undergo dialysis as well as in non-alcoholic fatty liver patients, serum levels of omentin increase. The cause of this increase in the amount of omentin in these patients is its defective degradation and excretion in renal patients or lack of synthesis of some inflammatory factors such as CRP in patients with liver disease (16-17). In 2013, a study by Wang and his colleagues showed that omentin is decreased in the serum of OSAS (obstructive sleep apnea syndrome) patients, while a study by Kar Kurt in 2014 showed the opposite result. In the Wang et al. study, cases had no history of any other illness (such as diabetes, tumors, or alcohol and drug abuse) other than OSAS, but in the other study performed by Kar Kurt et al. only OSAS patients without specific comorbidities in- cluding diabetes, CVD (cardiovascular diseases) and metabolic syndrome were included (18-19). The use of omentin reduces the inflammatory effects and also improves muscle cell proliferation in the culture of human smooth muscle cells of the aorta (20) and reducing the amount of omentin increases the formation of atherosclerotic ulcers by inducing inflammatory responses of macrophages through (5'AMP-activated protein kinase) AMPK-Akt signaling pathway (21) and omentin also reduces inflammatory responses in endothelial and vascular smooth muscle cells that are stimulated with TNF- $\alpha$ (22-23). Thus, omentin has anti-inflammatory properties (17). Based on the present study it can be said that a rise in the serum level of omentin in nonpatient smokers is due to its secretion from other sources. The result may be supported by the study conducted by Watanabe in 2016 that an increase in the amount of omentin in serum of patients with CAD (coronary artery disease) in spite of the decrease in the expression of omentin in the epicardial adipose tissue in these patients is due to the secretion of omentin from the macrophages in the atherosclerotic plaques (20).

Since the discovery of omentin, its role in tumorigenesis has been shown in a large number of studies. In women with EEC (Endometrioid Endometrial Cancer) and CAH (Complex Atypical endometrial Hyperplasia), the levels of serum omentin decrease in relation to BMI-matched healthy people .EEC is an inflammatory disease that is associated with obesity and diabetes (24). Also, in women with ovarian cancer the levels of serum omentin decrease. Besides, the power of proliferation, motility, and cellular invasion in these cancer cells is reduced by the effect of omentin (25), So that patients with high serum omentin have a longer life span than those with lower serum omentin. In this case, it is hypothesized that there may be a negative effect on cell proliferation (24). It has been proved in various studies that the level of serum omentin increases in prostate, colorectal and pancreatic adenocarcinoma cancers, while it decreases in RCC (Renal Cell Carcinoma) and Bladder cancer. It seems that increasing the amount of omentin in some cancers stimulates cell growth by triggering genomic instability and PI3K/Akt (phosphatidylinositol-3 kinase downstream effector) signaling pathways thereby contributing to

the pathogenesis of these cancers (26-29). On the other hand, omentin plays a major role in inflammatory responses and cellular differentiation and has a significant contribution to inducing apoptosis in cancer cells (30-31). Omentin stimulates apoptosis in cells through the activation of JAK signaling pathway and P53 upregulation mechanisms (30). It also inhibits inflammatory diseases via suppression of JNK (Jun N-terminal kinase) activation through the AMPK/eNOS (endothelial nitric oxide (NO) synthase) signaling pathway (22). Also omentin reduces the expression of VCAM-1 (vascular cell adhesion molecule-1) and ICAM-1 (intercellular cell adhesion molecule-1) (the molecules involved in the pathogenesis of cancer cells) adhesion molecules through inhibition of P38, JNK pathway and blocking of ERK/NF-K $\beta$ (extracellular signal-regulated kinase/nuclear transcription factor kappa B) pathway (23, 31). Another mechanism of omentin in triggering apoptosis 
in cells is increasing the bax/bcl- 2 protein ratio and activation of the caspase- 3 signaling pathway (30). Therefore, the reduction of omentin in RCC and ECC increases cellular proliferation and decreases apoptosis in cancer cells. In this study, we demonstrated that the circulation of omentin is decreasing in the lung cancer patients and the decrease in its amount in the smoker patients is significant compared to non-patient smokers.

About $85 \%$ of the total lung cancer cases were non-small cell lung cancer (NSCLC) which mainly includes squamous cell carcinoma (32) and adenocarcinoma, and these contain approximately 400,000 deaths each year in the world (32-33). Smoking is the main cause $(85-90 \%)$ of lung cancer (34), and the prevalence of SCC is more than of adenocarcinoma in smokers (33). Metastasis and recurrence are very common in SCC (32) and in the invasive types of the tumor with rapid initial growth (35). As shown in this study, the amount of serum omentin in SCC patients decreases more significantly than in patients afflicted with other lung malignancies.

\section{Conclusion}

Omentin-1 levels were found to be significantly lower in smoker lung cancer patients, irrespective of their general clinical conditions. These findings suggest that this adipokine might play some crucial role in the tumorigenesis of lung cancer via mechanisms that are active in lung cancer. Thus, the measurement of omentin in smokers may be considered as a significant factor in the prognosis of lung cancer in smokers and should be further investigated.

\section{Acknowledgments}

This research was funded by West Azerbaijan University of Medical Sciences and Health Services with the Grant No. 1393-04-32-1392. We would also like to thank Dr. Farhad Nemati and his colleagues in the medical laboratory for their assistance in the diagnosis of lung cancer in patients.

\section{Conflict of Interests}

The authors declare that they have no competing interests.

\section{References}

1. Wong M, Lao XQ, Ho KF, Goggins WB, Tse SL. Incidence and mortality of lung cancer: global trends and association with socioeconomic status. Sci Rep. 2017;7:14300.

2. Ferlay J, Shin HR, Bray F, Forman D, Mathers C, Parkin DM. Estimates of worldwide burden of cancer in 2008: GLOBOCAN 2008. Int J Cancer. 2010;127:2893-2917.

3. Ntikoudi E, Kiagia M, Boura P, Syrigos KN. Hormones of adipose tissue and their biologic role in lung cancer. Cancer Treat Rev. 2014;40:22-30.

4. Ouchi N, Ohashi K, Shibata R, Murohara T. Adipocytokines and obesity-linked disorders. Nagoya J Med Sci. 2012;74:19-30.

5. De Jager S, Pasterkamp G. Atheroprotective properties of human Omentin-1 in experimental atherosclerosis. Cardiovascu Res. 2016;110:1-3.

6. Zhou Y, Zhang B, Hao C, Huang X, Li X, Huang Y, et al. OmentinA Novel Adipokine in Respiratory Diseases. Int J Mol Sci. 2018;19, 73:1-16.

7. Tan BK, Adya R, Randeva HS. Omentin: A Novel Link between Inflammation, Diabesity, and Cardiovascular Disease. Trends Cardiovasc Med. 2010;20(5):143-8.

8. Wang Z, Nakayama T. Inflammation, a Link between Obesity and
Cardiovascular Disease. Mediators Inflamm. 2010:1-17.

9. Halabis M, Dziedzic M, Warchulinska J, Bystryk IK, Solski J. Omentin - a new adipokine with many roles to play. Curr Issues Pharm Med Sci. 2015;28:176-180

10. Lesna J, Ticha A, Hyspler R, Musi F, Bláha V, Sobotka L, et al. Omentin-1 plasma levels and cholesterol metabolism in obese patients with diabetes mellitus type 1: impact of weight reduction. Nutr Diabetes. 2015;5:1-6.

11. Tan BK, Ayda R, Farhatullah S, Chen J, Lehnert H, Randeva H. Metformin Treatment May Increase Omentin-1 Levels in Women With Polycystic Ovary Syndrome. Diabetes. 2010;59:3023-3031.

12. Grivennikov SI, Greten FR, Karin M. Immunity, Inflammation, and Cancer. Cell. 2010;140:883-899.

13. Mantovani A, Allavena P, Sica A, Balkwill F Cancer-related inflammation. Nature. 2008;454:436-444.

14. Carolan BJ, Harvey BG, De BP, Vanni H, Crystal RG. Decreased Expression of Intelectin 1 in the Human Airway Epithelium of Smokers Compared to Nonsmokers. J Immunol. 2008; 181:5760-5767.

15. RomO, Avezov K, Aizenbud D, Reznick AZ. Cigarette smoking and inflammation revisited. Respir Physiol Neurobiol. 2013; 187:5-10.

16. Yilmaz Y, Yonal O, Ramazan K, Alahdab YO, Eren F, Ozdogan O. Serum levels of omentin, chemerin and adipsin in patients with biopsyproven nonalcoholic fatty liver disease. Scand J Gastroenterol. 2011;46:91-97.

17. Sengul E, Duygulu G, Dindar S, Bunul F. Serum omentin-1, inflammation and carotid atherosclerosis in patients with non-diabetic chronic kidney disease. Renal Fail. 2013;35:1089-1093.

18. Wang Q, Feng X, Zhou C, Li P, Kang J. Decreased levels of serum omentin-1 in patients with obstructive sleep apnoea syndrome. Ann Clin Biochem. 2013;50:230-235.

19. Kar Kurt O, Tosun M, Alcelik A, Yilmaz B, Talay F. Serum omentin levels in patients with obstructive sleep apnea. Sleep Breath. 2014; 18:391-395.

20. Watanabe K, Watanabe R, Konii H, Shirai R, Sato K, Matsuyama TA, et al. Counteractive effects of omentin-1 against atherogenesis. Cardiovasc Res. 2016;110:118-128.

21. Cheng X. Elucidating the pathophysiological significance of circulating omentin levels: Is higher better? Atherosclerosis. 2016;251: 522-524.

22. Yamawaki H, Kuramoto J, Kameshima S, Usui T, Okada M, Hara Y. Omentin, a novel adipocytokine inhibits TNF-induced vascular inflammation in human endothelial cells. Biochem Biophys Res Commun. 2011;408(2):339-43.

23. Kazama K, Usui T, Okada M, Hara Y, Yamawaki H. Omentin plays an anti-inflammatory role through inhibition of TNF- $\alpha$-induced superoxide production in vascular smooth muscle cells. Eur J Pharmacol. 2012;686:116-123.

24. Holman LL, Onstad M, Zhang Q, Schmandt RE, Neal S, Munsell $\mathrm{MF}$, et al. Serum omentin concentration is a potential biomarker for complex atypical hyperplasia and endometrioid endometrial cancer. Gyneco Onco. 2014;133:2-207.

25. Onstad M, Au Yeung C, Holman LL, Schmandt RE, Zhang Q, Munsell MF, et al. Omentin: A potential tumor suppressor in the microenvironment associated with visceral obesity. Gyneco Onco. 2014;133:2-207.

26. Shen XD, Zhang L, Che H, Zhang YY, Yang C, Zhou J, et al. Circulating levels of adipocytokine omentin-1 in patients with renal cell cancer. Cytokine. 2016;77:50-5.

27. Fazeli MS, Dashti H, Akbarzadeh S, Assadi M, Aminian A, Keramati MR, et al. Circulating levels of novel adipocytokines in patients with colorectal cancer. Cytokine. 2013;62(1):81-5.

28. Uyeturk U, Sarıcı H, Kın Tekce B, Eroglu M, Kemahlı E, Uyeturk $\mathrm{U}$, et al. Serum omentin level in patients with prostate cancer. Med Oncol. 2014;31(4):923-926.

29. Zhang Y, Yang Ch, Hao Z, Shen X, Zhou J, Zhang L, et al. Circulating levels of adipocytokines omentin-1 and adiponectin in patients with bladder cancer. Int J Clin Exp Pathol. 2016;9(11):11718-11726.

30. Zhang YY, Zhou LM. Omentin-1, a new adipokine, promotes apoptosis through regulating Sirt1-dependent p53 deacetylation in hepatocellular carcinoma cells. Eur J Pharmacol. 2013;698:137-144.

31. Ohashi K, Shibata R, Murohara T, Ouchi N. Role of anti-inflammatory adipokines in obesity-related diseases. Trends Endocrinol Metab. 2014;25(7):348-355.

32. Li B, Chen P, Wang JH, Li L, Gong JL, Yao H. Ferrerol overcomes the invasiveness of lung squamous cell carcinoma cells by regulating 
the expression of inducers of Epithelial Mesenchymal Transition. Microb Pathog. 2017;112:171-175.

33. Park SK, Cho LY, Yang JJ, Park B, Chang SH, Lee KS et al. Lung cancer risk and cigarette smoking, lung tuberculosis according to histologic type and gender in a population based case-control study. Lung Cancer. 2010;68(1):20-26.

34. Ermin S, Çok G, Veral A, Kose T. The role of apelin in the assessment of response to chemotherapy and prognosis in stage 4 nonsmall cell lung cancer. Turk J Med Sci. 2016;46(5):1353-1359.

35. Goldenberg A, Ortiz A, Kim SS, Jiang SB. Squamous cell carcinoma with aggressive subclinical extension: 5-year retrospective review of diagnostic predictors. J Am Acad Dermatol. 2015;73(1):120-126. 